\title{
Outcome Analysis of Sport Related Facial Fractures by Conventional Radiography and Facial CT: The Diagnostic Accuracy in Different Imaging Modalities
}

\author{
DALIA S. ANWAR, M.D. \\ The Department of Radio-Diagnosis, Faculty of Medicine, Zagazig University, Egypt
}

\begin{abstract}
Background: Injury to the facial region may lead to life threatening situations, it is difficult to physically examine the patient with facial trauma. The growing frequency and magnitude of road traffic accidents, as well as the increase in episodes of urban violence, have made these traumas a form of social disease. Multidetector Computed Tomography (MDCT) is the imaging modality of choice and is one of the most important imaging tools in evaluation of patients with sport related maxillofacial trauma. It helps in detecting the exact site, number and extent of fractures, displacement of fragments and soft tissue injuries.

Aim of Study: The aim of this study is to detect sport related different facial fractures by using conventional radiography and Multi Detector Computed Tomography (MDCT).

Patients and Methods: Twenty eight patients were referred to Department of Radiodiagnosis, Zagazig University Hospitals for this prospective cross-sectional study.

In this study, 28 patients with 60 facial fractures were examined by multidetctor $\mathrm{CT}$ from the most common fracture was orbital fracture seen in 14 cases $(50 \%)$.

Our study included 28 patients who sustained sport trauma to the facial skeleton with age range from 17-51 years old. Conventional plain radiography and MDCT were performed to all patients.

Results: In this study, males were constitute most of the patients with number of 22 patients which represents (78. $6 \%$ ) of the total while number of female patients was 6 which represents $(21.4 \%)$ of the total.

Conclusion: Facial injuries are commonly encountered emergencies which needs early diagnosis and management. Road traffic accidents and social violence are the common reasons which have led to increase in the frequency of maxillofacial injuries. However sport related facial injuries is still a common cause, the complex anatomies of the facial bones require multiplanar imaging techniques for a detailed evaluation
\end{abstract}

Key Words: Multi detector computed tomography - SportFacial fractures - Complication.

Correspondence to: Dr. Dalia S.

Anwar,E-Mail: dodoradiology@gmail.

\section{Introduction}

FACIAL fractures cases are serious cases on all occasions, the most common causes of these types of fractures are road accidents, sport trauma, violence, or falls from height. The location and extent of the fracture must be evaluated in accurate manner providing clinicians illustration of complicated cases with combined soft-tissue or sensory system injury, in addition, information required to set surgical steps [1].

\section{Simple facial fractures:}

Fractures involving a single facial buttress are alveolar process fractures, frontal sinus fracture, isolated zygomatic arch fracture, mandibular fracture, nasal bone fracture,orbital blow out fracture and paranasal sinus fracture.

\section{The complex facial fractures:}

Is Le Fort fracture. It has several types Type I ( horizontal fracture): It traveling through the nasal septum crosses lower than the zygomaticomaxillary junction and the pterygomaxillary junction as well to pass through the pterygoid plates. Type II (pyramidal fracture): It extends from the below the naso-frontal junction of the maxilla, infero-laterally withen the lacrimal bones, and frontal wall of the maxillary sinus; it passes below the zygoma. Type III (transverse), begins at the nasofrontal and frontomaxillary sutures and passes posteriorly along the inner wall of the orbit [2].

Maxillofacial traumatology is common in adolescent [3]. Extensive facial trauma and associated hematoma and swelling can compressing airways.

\footnotetext{
Abbreviations:

MDCT: Multidetctor Computed Tomography.
} 
Fractures to the bones of orbital cavities can result in damage to the optic nerves or vessels, causing blindness or herniation of the globe; zygomatic bone fractures can result in fractures to the orbital floor, displacing the globe. Infection as well can result from facial fractures and associated trauma

$[4,5]$.

There is an obsessive need for radiography to identify such fractures, to detect their morphology and extension, and to evaluate nearby soft-tissue damage [6].

There are other imaging modalities for assessing facial trauma, but Multidetector Computed Tomography (MDCT) imaging is the ideal method for rapid and accurate evaluation of facial trauma [7,8]. This modality has an accurate role in the detection and assessment of complex fracture types and the expectation of complications associated with certain types, locations, and patterns of fractures [9]. Data acquisition and reconstruction times have reduced by technological advances in Computerized Tomography (CT) so that three-dimensional (3D) CT images of facial injuries may be generated rapid and with less efforts [10].

\section{Patients and Methods}

Twenty eight patients with age range from 1751 years old were referred from ENT Department to Department of Radiodiagnosis, Zagazig University Hospitals from April 2019 - October 2019, complaining of sport facial trauma and facial pain, hematomas, we took Written consent was requested from all studied cases then we did this prospective cross-sectional study included in our research.

\section{Inclusion criteria:}

- Patients exposed to sport trauma with clinical doubt of facial fracture.

- Patients with normal X-ray but clinically complain.

\section{Exclusion criteria:}

- Patient has facial trauma not related to sport.

- Patient refuse to complete the study.

Methods: All patients were subjected to the following:

Clinical assessment:

1- Complete clinical data.

2- Clinical examination: Patients assessed by the emergency doctors and redirected to the radiol-
Radiodiagnostic imaging:

1- Conventional radiography.

\section{2- MDCT examination:}

- Examination Technique: MDCT examination of the face was applied for all patients included in this study. All patients were examined with a 128channel MDCT machine (Philips ingenuity 128) by the following parameters: $1 \mathrm{~mm}$; slice thickness, detector row configuration, $128 \times 1 \mathrm{~mm}$; collimation, $1.25 \mathrm{~mm}$; pitch, 1.375 ; reconstruction interval, $1 \mathrm{~mm} ; 300 \mathrm{mAs} ; 120 \mathrm{kVp}$. To have direct axial scans, we scanned all patients in supine position with head first towards the gantry without gantry tilt. No specific patient procedures was required except peaceful breathing. MDCT protocol consists of volumetric data acquisition introductory below the mandible and finishing when frontal sinuses are cleared. Direct coronal images in traumatic maxillofacial fractures are difficult to obtain. Post processing, the scans were reconstructed and reviewed. Multiplanar Reconstructions (MRP) were done using the software in coronal and sagittal planes. The thin axial slices travel from the MDCT scanner to a workstation by the Picture Archiving and Communication System (PACS) for reconstruction of 3D images which are important adjuncts to axial and MRP images for evaluation of spatial relationships. However, we should not use only 3D images for the detection and localization of fractures. Multidetector CT had transformed CT from a trans axial cross-sectional technique into a true 3D imaging modality for cut planes as well as admirable 3D displays of the data volume.

\section{Image interpretation:}

All axial images and postprocessing images were examined for the following items: Facial fractures existence, the extent of fractures and soft tissues complication.

\section{Final diagnosis of the patients:}

Final diagnosis of the patients was reached by operative data during reduction and fixation of the fracture.

\section{Results}

Our study included 28 patients who sustained sport trauma to the facial skeleton with age range from 17-51 years old. Conventional plain radiography and MDCT were performed to all patients.

In this study, males were constitute most of the patients with number of 22 patients which represents $(78.6 \%)$ of the total, while number of female patients was 6 which represents $(21.4 \%)$ of the total. 
About the age distribution in 28 patients with facial skeletal trauma, the range of age was from 17 to 51 years, and 29 years was the mean age; the most frequent age group was $\leq 30$ years which represents $67.9 \%$ of the total and the least frequent age group was $>30$ years in the form of 9 patients which represents only $32.1 \%$ of the total (Table 1 ).

Table (1): Age and gender distribution in 28 patients with facial trauma.

\begin{tabular}{cl}
\hline & $\mathrm{n}=28$ \\
\hline Age (years): & \\
Mean \pm SD & $29 \pm 10.5$ \\
Range & $17-51$ \\
Age groups: & \\
$\leq 30$ & $19(67.9 \%)$ \\
$>30$ & $9(32.1 \%)$ \\
Gender: & \\
Male & $22(78.6 \%)$ \\
Female & $6(21.4 \%)$ \\
\hline
\end{tabular}

In this study, 28 patients with 60 facial fractures were examined by multidetctor CT from the most common fracture was orbital fracture seen in 14 cases $(50 \%)$ (Table 2).

Table (2): Distribution of different facial fractures in 28 patients according to the MDCT findings.

\begin{tabular}{lll}
\hline & No. & $\%$ \\
\hline Orbital fracture & 14 & 50 \\
Nasal fracture & 12 & 42.9 \\
Maxillary sinus wall fracture & 9 & 32.1 \\
Zygomatico-maxillary complex fracture & 5 & 17.9 \\
Mandibular fracture & 5 & 17.9 \\
Fracture maxilla & 4 & 14.3 \\
Frontal sinus fracture & 3 & 10.7 \\
Le Fort II fracture & 2 & 7.1 \\
Le Fort I fracture & 2 & 7.1 \\
Le Fort III fracture & 2 & 7.1 \\
Naso-orbito-ethmoidal fracture & 1 & 3.6 \\
Isolated zygomatic arch fracture & 1 & 3.6 \\
\hline
\end{tabular}

In (Table 3) MDCT detected complex fractures in the form of zygomatico-maxillary complex fracture in 5 cases, le fort fracture I in 2 cases, le fort II fracture in 2 cases, le fort III fracture in 2 cases, NOE fracture in one case. Therefor, zygomatico-maxillary complex fracture is the most common complex fractures seen in 5 cases (17.9\%).

Table (3): Incidence of complex facial fractures in 28 patients with maxillofacial trauma.

\begin{tabular}{lcl}
\hline & No. & $\%$ \\
\hline ZMC & 5 & 17.9 \\
Le Fort II & 2 & 7.1 \\
Le Fort I & 2 & 7.1 \\
Le Fort III & 2 & 7.1 \\
NOE fracture & 1 & 3.6 \\
\hline
\end{tabular}

\section{Discussion}

The facial skeleton is anatomically classified into five different regions: Nasal, orbital, zygomatic, maxillary and mandibular. The nasal bones, lacrimal bones, and frontal process of the maxilla, nasal septum and ethmoid cells are the main component of the nasal bone. Seven bones comprises the orbital region; the maxillary, zygomatic and frontal bones comprise the external orbital skeleton, while the internal orbit includes the lacrimal, palatine, ethmoid and sphenoid bones. The zygomatic process of the frontal bone, the zygomatic bone and the zygomatic process of the maxilla constitute the zygomatic region. The maxillary region includes the alveolar process and the bony components of the hard palate. Eventually, the mandibular region is made up of the mandible and the temporomandibular joint [10].

Injury to the facial region may be associated with dangerous situations i.e., encroachment on airways and diffuse blood loss. Due to soft tissue swelling and injury, it is difficult to physically examine the patient with facial trauma [11,12].

Imaging in the trauma mainly used to evaluate the exact number and extension of facial fractures, with special comments about injuries to functional points of the face that affect the cosmetic outcomes [13].

In intense injuried patients, MDCT check gives the best, safe and sensibly fast determination of the unpredictable example of different cracks of facial skeleton as compaired to routine radiographics $[\mathbf{1 4 , 1 5}]$.

The advantage of MDCT is 3D reconstruction and multiplanar reformation in coronal and sagittal planes which are extremely helpful in assessing bone in comminuted and displaced fractures including multiple planes that helps the surgeons for appropriate planning and management.

In our study, there were 28 patients males were more common than females with number of 22 patients which represents $(78.6 \%)$ of the total, while number of female patients was 6 which represents $(21.4 \%)$ of the total. This was in agreement with Ahmad et al., [16] who reported that guys speak to $(70 \%)$ of the study and females speak to $(30 \%)$ of the study.

In our study, range of ages from 17 to 51 years with mean age of 29 years; the most frequent age group was $\leq 30$ years which represents $67.9 \%$ of the total and the least frequent age group was $>30$ 
years in the form of 9 patients which represents only $32.1 \%$ of the total. Ahmad et al., [16] reported that range of age of the patients from 12 to 70 years. Maximum number of cases $(55 \%)$ was in 1130 years of age group followed by (20\%) 3140 years of age.

In our study, 28 patients with 60 facial fractures were examined by MDCT. We found that the most common fracture was orbital fracture seen in 14 cases $(50 \%)$. This was relatively in agreement with Abdel Wahab et al., [17] who reported that orbital cracks were the most successive breaks and were found in 22 cases representing around $73 \%$ and the nasal breaks found in 19 cases representing $63 \%$.

Ahmad et al., [16] orbital floor fracture was found in 21 patients (35\%), 18 patients had maxillary sinus wall fracture $(30 \%)$, fractures of the nasal bone were found in $17(28.33 \%)$, mandiblular fracture in 15 (25\%), 13 patients had zygomaticmalar complex fracture $(21.66 \%)$, orbital wall fracture was seen in $11(18.33 \%), 9$ patients had naso ethmoidal fractures (15\%), frontal sinus fracture was noted in 7 patients $(11.66 \%)$, Le fort fracture in 1 case $(1.66 \%)$ and others $3(5 \%)$. The orbital floor fracture had the highest percentage ( $35 \%$ ) followed by maxillary sinus wall fracture ( $30 \%)$ and nasal bone fracture $(28.33 \%)$.

But, this was not in agreement with Hwang and You [18] who reported that the orbital divider breaks were the third in exploration representing $(7.6 \%)$ just of the analyzed cases after the fractures of the nasal bones and mandibular bone.

In our study, MDCT examination detected simple fractures in the form of: Orbital wall fracture in 7 cases, nasal bone fracture seen in 4 cases, mandibular fracture seen in 3 cases, maxillary sinus wall fracture seen in 2 cases, fracture maxilla ( hard palate and alveolar proceess) in 2 cases, isolated zygomatic arch fracture in one case and frontal sinus fracture in one case. Therefore, the most common simple maxillofacial fracture was orbital wall fracture seen in 7 patients (Table 4).

Table (4): Incidence of simple facial fractures in 28 examined patients with facial trauma.

\begin{tabular}{lcc}
\hline & No. & $\%$ \\
\hline Orbital wall fracture & 7 & 25 \\
Nasal fracture & 4 & 14.3 \\
Mandibular fracture & 3 & 10.7 \\
Maxillary sinus wall fracture & 2 & 7.1 \\
Fracture maxilla & 2 & 7.1 \\
Isolated zygomatic arch fracture & 1 & 3.6 \\
Frontal sinus fracture & 1 & 3.6 \\
\hline
\end{tabular}

MDCT detected complex fractures in the form of zygomatic-maxillary complex fracutre in 5 cases, Le Fort II fracture in 2 cases, Le Fort I fracture in 2 patients, Le Fort III fracture in 2 cases and NOE fracture in one case. Therefore, zygomaticomaxillary complex fracture is the most common complex fractures seen in 5 cases $(17.9 \%)$.

In our study, MDCT detected orbital bony wall fractures in 14 patients. MDCT detected orbital floor fractures in 8 patients representing about $57.1 \%$ of all orbital bone fractures, lateral wall fracture of orbital bone in 6 patients $(42.86 \%)$, medial orbital wall fracture in 4 patient $(28.6 \%)$ and orbital roof fracture in 3 patients accounting for about $21.4 \%$. Therefore, orbital floor fracture is the most common orbital bony wall fracture seen in 8 cases $(57.1 \%)$ (Table 5).

Table (5): Distribution of orbital wall fractures according to the site of the fracture.

\begin{tabular}{lll}
\hline & No. & $\%$ \\
\hline Orbital floor & 8 & 57.1 \\
Lateral orbital wall & 6 & 42.86 \\
Medial orbital wall & 4 & 28.6 \\
Orbital roof & 3 & 21.4 \\
\hline Total & 14 & 100 \\
\hline
\end{tabular}

This was in agreement with Ahmad et al., [16] who reported that orbital floor fracture was the most common fracture accounting for $36 \%$. Among the orbital floor fractures in 21 patients $7(33.33 \%)$ had bursting fracture of the orbit and 3 (14.28\%) patients had associated with inferior rectus muscle and orbital fat herniation into the maxillary sinus.

But, this was not in agreement with Abdel Wahab et al., [17] reported that frequency of orbital divider cracks as per the site spoke to as: Average divider $63.6 \%$, horizontal divider $59 \%$, story $41 \%$ and rooftop $31.8 \%$ of cases. Nasal fracture was seen in 19 cases representing for about $63 \%$ and maxillary bone fracture was detected in 17 cases accounting for about $56 \%$.

In all instances of orbital breaks, we should evaluate the globe, the optic nerve and infraorbital delicate tissue, we should note the vicinity or nonattendance of extraocular muscle herniation. Muscle ensnarement is a surgical crisis. MDCT discoveries in trap-entryway cracks can be very inconspicuous, and might be over looked on the off chance that they are not effectively however. One characteresic finding in such cracks is the loss of substandard rectus muscle in the circle, herniation of second rate rectus muscle and orbital fat in 
the maxillary sinus. Coronal reformat are basic in the assessment of the orbital floor.

Mandibular fractures comprises of the fracture of symphysis, body or horizontal ramus, alveolar process, coronoid process, angle, ascending ramus, and mandibularcondyle $[\mathbf{1 5}, \mathbf{1 6}]$. Pain, trismus, difficulty in chewing, malocclusion, swelling and fractures are the common presentations of the mandibular trauma [16]. Any asymmetry in the occlusion is highly suggestive of mandibular fracture [6].

In our study, MDCT detected fracture mandible in 5 cases. MDCT detected fracture of mandibular body in 2 patients. Fracture of mandibular symphysis was detected in 2 patients. Fracture of the condylar process was detected in one patient. Also, MDCT detected coronoid process in one patient. The distribution of mandibular fractures according to the fracture site (Table 6).

Table (6): Distribution of mandibular fractures according to fracture site.

\begin{tabular}{lll}
\hline & No. & $\%$ \\
\hline Body & 2 & 40 \\
Symphysis & 2 & 40 \\
Condyle & 1 & 20 \\
Coronoid process & 1 & 20 \\
\hline Total & 5 & 100 \\
\hline
\end{tabular}

This was relativety in agreement with Ozakaya et al., [19] who reported that $30 \%$ had isolated mandibular fracture, while $10 \%$ had mandibular fracture associated with other maxillofacial fractures.

In our study, plain X-ray detected simple facial fractures in 17 patients and 6 complex facial fractures among 28 patients with facial fractures, while MDCT detected simple facial fractures in 20 patients and 12 complex facial fractures in 8 patients ( Table 7).

Table (7): Incidence of different complex facial fractures detected by X-ray and MDCT.

\begin{tabular}{lcc}
\hline & X-ray & MDCT \\
\hline ZMC fracture & 5 & 5 \\
Le Fort II & 0 & 2 \\
Le Fort I & 0 & 2 \\
Le Fort III & 0 & 2 \\
NOE fracture & 1 & 1 \\
\hline Total & 6 & 12 \\
\hline
\end{tabular}

Mithani M., [20] reported that $50 \%$ of the patients with maxillofacial trauma had intracranial injuries. Motamedi et al., [21] reported that Le Fort II break was the most common among the Le Fortbreaks with a percent of $7.6 \%$.

Abdel Wahab et al., [17] said that the zygomatico-maxilla accounting about (27\%). Naso-orbitoethmoidal fractures were detected in 6 patients accounting for $20 \%$, they represent the commonest group with complex fractures.

In our study, we found that in simple fractures, conventional plain radiography and MDCT had sensitivity of $85 \%$, specificity of $87.5 \%$, positive predictive value of $94.4 \%$ and negative predictive value of $70 \%$. In complex fractures, they had sensitivity of $50 \%$, specificity of $93.8 \%$, positive predictive value of $85.7 \%$ and negative predictive value of $71.4 \%$ (Table 8). Schuknecht and Graetz [ 22] reported that the sensitivity of Multidetector Computed Tomography (MDCT) to detect simple maxillofacial fractures is $100 \%$, whereas conventional X-rays had only $86 \%$ sensitivity.

Table (8): Diagnostic performance of MDCT in diagnosis of simple and complex fractures.

\begin{tabular}{lrrrr}
\hline & Sensitivity Specificity PPV NPV \\
\hline Simple fracture & $85 \%$ & $87.5 \%$ & $94.4 \%$ & $70 \%$ \\
Complex fracture & $50 \%$ & $93.8 \%$ & $85.7 \%$ & $71.4 \%$ \\
\hline
\end{tabular}

Raju et al., [23] identified and classified the facial fractures after the use of multislice Computed Tomography (CT) as well as he identifies the advantages of three-dimensional (3D) rendered images in comparison to two-dimensional axial images in evaluating maxillofacial injuries. They demonstrated that MDCT provides excellent spatial resolution in the evaluation of fractures in the maxillofacial region. 3D rendered images provide a better evaluation of the extension of the fractures and the separation of the bony particles, especially in the mandible and zygomatic bone thus helping in the quicker and better communication of the information to the surgeon. 3D images were also better in the identification of Le Fort fracture lines. MDCT is an accurate, noninvasive technique for the evaluation of patients with maxillofacial injuries with an added advantage of shorter scan time and easy availability. 


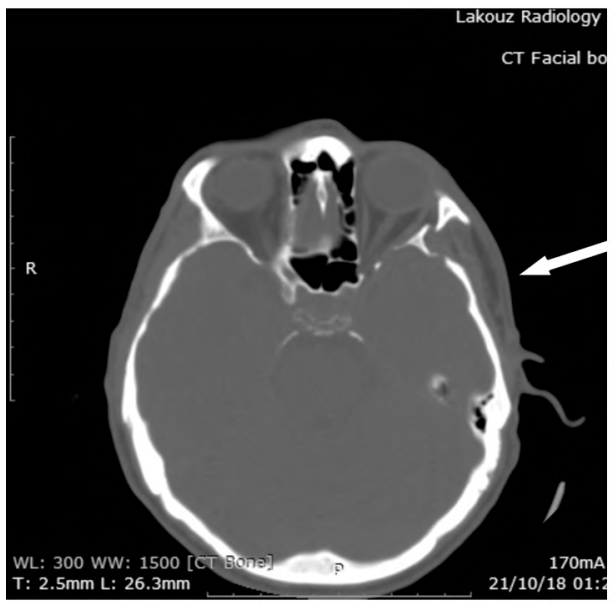

Fig. (1A): Axial MDCT image of facial bones (bone window): Shows comminuted fracture of left lateral orbital wall (white arrow).

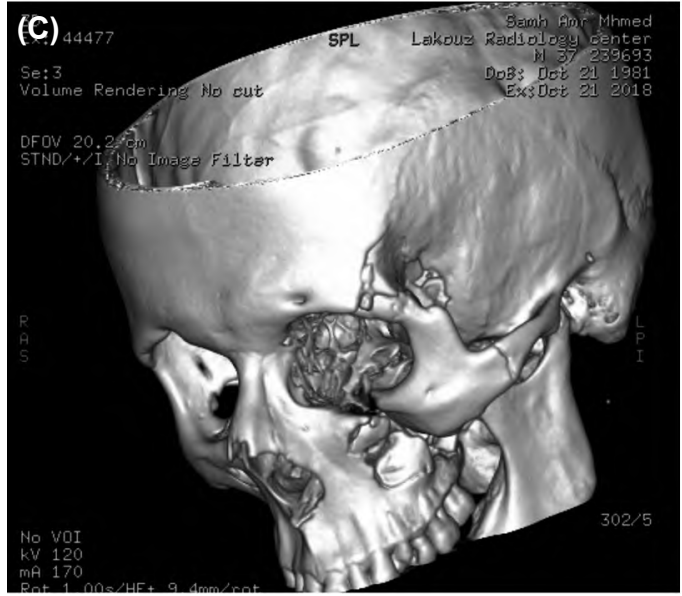

Fig. (1C,D): 3D reconstruction images show overview of the fractures. Diagnosis: Left ZMC fractures with orbital wall fractures.
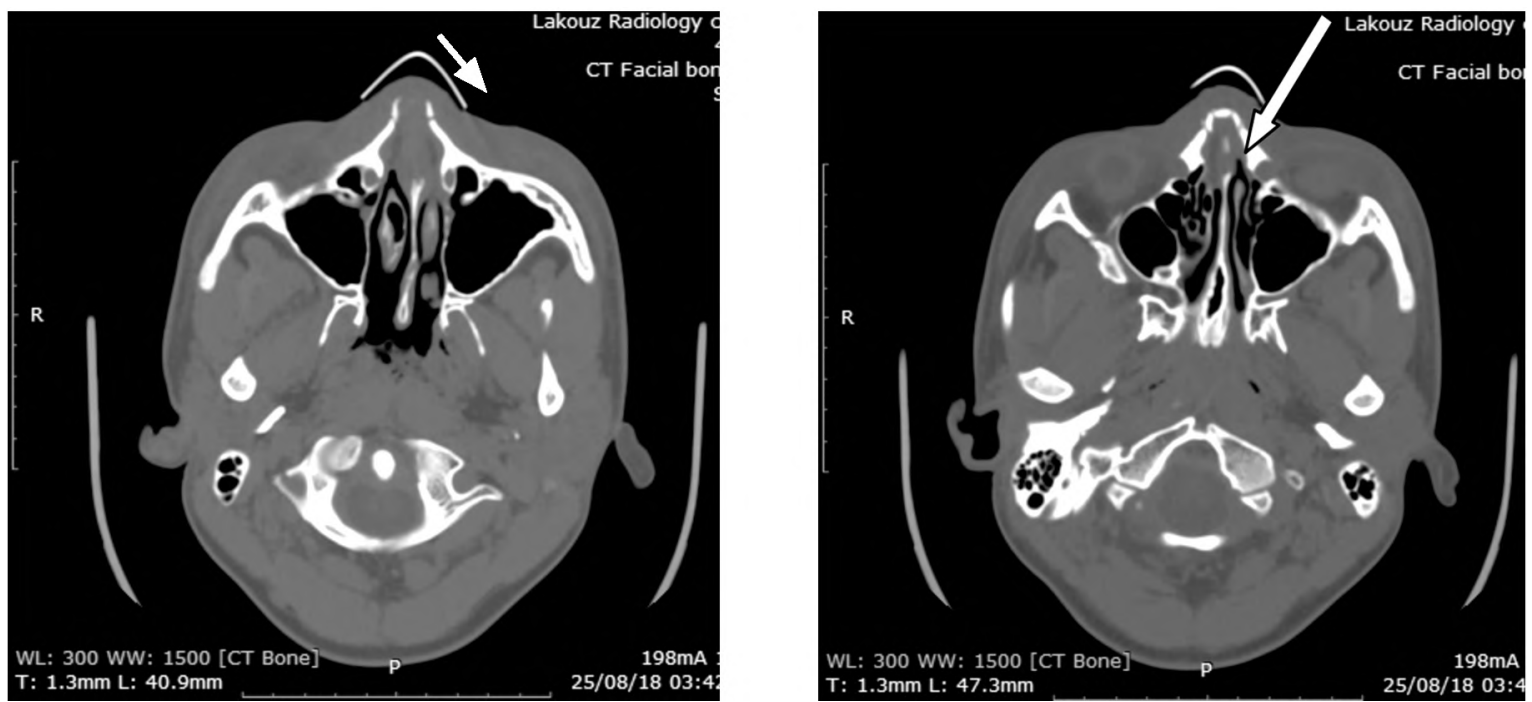

Fig. (2A,B): Axial, MDCT images of facial bones (bone window): Show comminuted fracture of both right and left nasal bones. Intact nasolacrimal ducts. (White arrow).

Diagnosis: Bilateral nasal bone fractures. 
So, we found in our study that multidetector CT is the examination of decision and is the methodology frequently utilized for imaging assessment as a part of patients of maxillofacial injury. It gives better outline of rigid and delicate tissue highlights, offers both multiplanar and three-dimensional picture remaking, and can be performed more rapidly than radiography, with less demanding patient situating. Precise depiction of facial cracks and intricacies is of fundamental significance for surgical arranging and suitable administration.

\section{Conclusion:}

Facial injuries are commonly encountered emergencies which needs early diagnosis and management. Sport related trauma is a common reason which have lead to increase in the frequency of maxillofacial injuries. The complicated anatomies of the facial bones need multidetector imaging method for a detailed fracture detection. The aim of imaging is to describe the site and exact number of facial fractures and associated soft tissue complication.

MDCT is the optimal imaging modality for detection of facial skeletal fractures, as it can visualize complicated injuries without need of conventional radiography or clinical examination. It supplies better spatial resolution, which allows multiplanar reformations, and 3D reconstructions, providing high diagnostic accuracy and road map for surgery. Fracture fragments displacement and rotation are easily determined by MDCT and 3D MDCT is the best modality for detection of the relationships of bone fragments in complex facial injuries. So after stabilization of the traumatized patient, MDCT is often the first and the most important imaging procedure a polytraumatized patient will need.

\section{References}

1- AGARWAL A., KUMAR N. and SHARMA N.: 2D and 3D CT scan-A diagnostic adjunct or necessity in maxillofacial trauma. Indian Journal of Dentistry, 3 (4): 1859, 2012.

2- AVERY LAURA L., SRINIVAS M. SUSARLA and ROBERT A NOVELLINE: Multidetector and three-dimensional CT evaluation of the patient with maxillofacial injury. Radiology Clinics North America, 49: 183-203, 2011.

3- BURNHAM R.: Management of panfacial injuries: Bottom up or top down. Challenging Concepts in Oral and Maxillofacial Surgery: Cases with Expert Commentary, 42, 2016.

4- COX A.J.I.: Nasal fractures-The details. Facial Plastic Surg., 16: 87-94, 2000.

5- ESKITASCIOGLU T., OZAZGAN I., CORUH A., et al.: Fractures of the mandible: A 20-year retrospective analvsic of 753 patients, Turkish Journal of Trauma \& Emergency Surgery, 19 (4): 348-56, 2014.

6- ROMEO A., PINTO A., CAPPABIANCA S., SCAGLIONE M. and BRUNESE L.: Role of multidetector row computed tomograghy in the management of mandible traumatic lesions. Semin. Ultrasound CT MRI, 30: 174 $80,2009$.

7- ELLIS E. and THROCKMORTON G.S.: Treatment of mandibular condylar process fractures: Biological considerations. J. Oral Maxillofac. Surg., 63 (1): 115-34, 2005.

8- AVERY LAURA L., SRINIVAS M. SUSARLA and ROBERT A. NOVELLINE: Multidetector and threedimensional CT evaluation of the patient with maxillofacial injury. Radiology Clinics North America, 49: 183-203, 2011.

9- SALONEN E.M., KOIVIKKO M.P. and KOSKINEN S. K.: Multidetector computed tomography imaging of facial trauma in accidental falls from heights. Acta. Radiol. ,48 (4): 449-55, 2007.

10- SAIGAL K., WINOKUR R.S., FINDEN S., TAUB D. and PRIBITKIN E.A.: Use of three dimensional computerized tomography reconstruction in complex facial trauma. Arch. Facial Plast. Surg., 21: 214-9, 2005.

11- MIGUEL S.C., JASON W., NADINE E.A., et al.: Epidemiology and management of maxillofacial fractures in an Australian trauma centre; Journal of Plastic, Reconstructive HYPERLINK "http://www.sciencedirect.com/ science/journal/17486815"\&HYPERLINK "http:// www.sciencedirect.com/science/journal/17486815" Aesthetic Surgery, 67 (2): 183-9, 2014.

12- PERRY M., DANCEY A., MIRESKANDARI K., et al.: Emergency care in facial trauma-a maxillofacial and ophthalmic perspective. Injury, 36: 875-96, 2005.

13- MEHTA N., BUTALA P. and BERNSTEIN M.P.: The Imaging of Maxillofacial Trauma and its Pertinence to Surgical Intervention. Radiol. Clin. N. Am., 50: 43-57, 2012.

14- PATHRIA M.N. and BLASER S.I.: Diagnostic imaging of craniofacial fractures. Radiol. Clin. North Am., 27: 839-53, 1989.

15- AGARWAL A., KUMAR N. and SHARMA N.: 2D and 3D CT scan-A diagnostic adjunct or necessity in maxillofacial trauma. Indian Journal of Dentistry, 3 (4): 1859, 2012

16- AHMAD K., RAUNIYAR R.K., KUMAR M.G., et al.: Multidetector computed tomographic evaluation of maxillofacial trauma. Asian Journal of Medical Sciences, 5 ( 4): 39-44, 2014.

17- ABDEL WAHAB M.A., IBRAHEIM M.A. and OSMAN N. M.: The role of multi detector computerized tomography in evaluation of maxillofacial fractures. The Egyptian Journal of Radiology and Nuclear Medicine HYPERLINK " http://www.sciencedirect.com/science/journal/0378603X/ 45/1", 45 (1): 97-104, 2014.

18- HWANG K. and YOU S.H.: Analysis of facial bone fractures: An 11-year study of 2094 patients. Indian J. Plast. Surg., 43 (1): 42-8, 2010.

19- OZAKAYA O., TURGUT G. and KAYAKLI M.U.: A retrospective study on the epidemiology and treatment 
maxillofacial fractures. Ulus. Travma. Acil. Cerrahi. Dreg., 15 (3): 262-6, 2009.

20- MITHANI M.: Maxillofacial fractures in Hamedan province, Iran: A retrospective study (1987-2001): J. of craniomaxillofacial. Surg., 32 (1): 28-34, 2007.

21- MOTAMEDI M.H., DADGAR E. and EBRAHIMI A.: Curbing Road Traffic Accidents-The Major Cause of Facial Fractures. International Journal of Emergency
Mental Health and Human Resilience, 16 (69-70): $1522-$ $4821,2014$.

22- SCHUKNECHT B. and GRAETZ K.: Radiologic assessment of maxillofacial, mandibular and skull base trauma. Eur. Radiol., 15 (3): 560568, 2005.

23- RAJU N.S., ISHWAR P. and BANERJEE R.: Role of multislice computed tomography and three-dimensional rendering in the evaluation of maxillofacial injuries. J. Oral. Maxillofac. Radiol., 5: 67-73, 2017.

\section{تحليل نتائج كسور الوجه المتعلقة بالرياضة

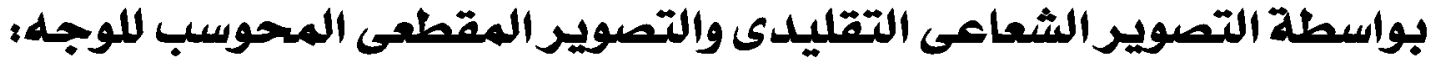

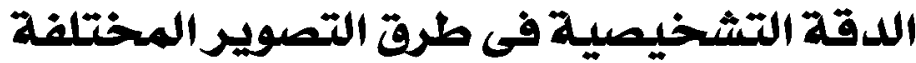

الهدف: الفرض من هذه الدراسة هو الكثف عن كسور الوجه المختفة المتعلقة بالرياضة بإستخدام التصوير الشعاعى التمليدى والتصوير

المقطعى المحوبسب متعدد الكاشفات (MDCT).

الخلفية: قد تؤدى إصابة منطقة الوجه إلى مواقف تهدد الحياة، فمن الصعب فحص المريض جسدياً بصدمة فى الوجه. إن تزايد وتيرة

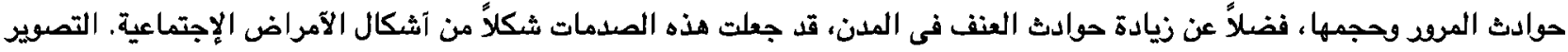

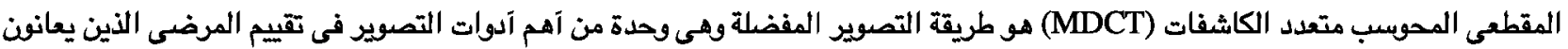

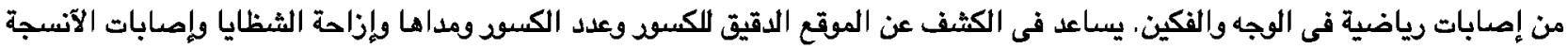
الرخوة.

الطريقة: تمت إحالة ثمانية وعشرين مريضاً إلى قسم التشخيص الإشعاعى بمستشفيات جامعة الزتازيق لإجراء هذه الدراسة المقطعية

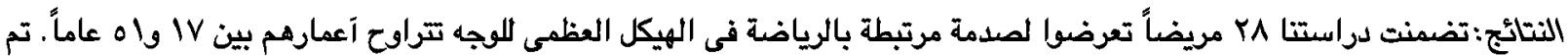

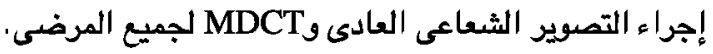

الخلاصة : إصابات الوجه هي حالات طارئة شائعة تحتاج إلى تشخيص مبكر ومعالجة. تعد حوادث المرود على الطرق والعنف في الرياضية

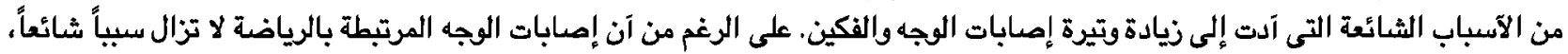
فإن التشريح المعقد لعظام الوجه يتطلب تقنيات تصوير متعددة الآسطع لإجراء تقيبيم مفصل. 